\title{
ARGUMENTACIÓN Y SENTENCIA
}

\author{
Mario Alberto Portela \\ Universidad Nacional de Mar del Plata (Argentina)
}

\section{Operadores jurídicos}

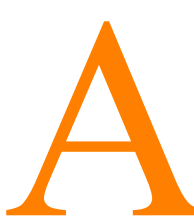

los efectos de presentar el tema denominaré operadores jurídicos a los jueces, abogados y juristas, esto es, a las personas que como tales o en calidad de órganos se dedican a aplicar y sistematizar normas jurídicas. Siguiendo una clásica distinción de Hart se podría decir que mientras los jueces y abogados trabajan desde un punto de vista interno al sistema, los juristas suelen hacerlo desde el punto de vista externo.

Los operadores internos, en los tiempos que corren, se han mostrado incapaces para cumplir adecuadamente la principal función social que se les encomendara, la de resolver conflictos, ya que no son eficientes para solucionarlos. Entre los múltiples motivos que ocasionan esta situación se encuentra el que se origina en los vicios argumentativos de las sentencias judiciales que originan carencias o falta de fundamentación de las mismas.

\section{Sentencia}

Es el acto jurisdiccional que pone fin a un conflicto dirimido en sede judicial. Requiere de un juicio previo sustanciado ante jueces imparciales, con ciertas garantías específicas y con todos los requisitos de la teoría y normativa procesales.

Pero además, para cumplir adecuadamente su objetivo, la sentencia debe estar fundada. Éste es un requisito preprocesal que deriva de la exigencia de razonabilidad y racionalidad que viene normativamente exigido por los arts. 14 y 28 de la Const. Nac. El mismo requisito de fundamentación vale para el acusador y el defensor en un proceso penal o el actor y el demandado en un juicio privado. Aunque el principio de razonabilidad no fuera explícito en nuestra constitución, el mismo es esencial por cuanto deriva del principio republicano de gobierno y del debido proceso adjetivo.

Una de las últimas preocupaciones de la Filosofía jurídica pasa por el desarrollo de la teoría de la argumentación, especialmente cuando se dirige 
a tratar de buscar fundamentos adecuados para que los operadores jurídicos cumplan adecuadamente su quehacer cotidiano.

\section{Razonamiento judicial}

Desde antiguo se sabe que el razonamiento judicial es idéntico a un silogismo que contiene una conclusión derivable de dos premisas, una fáctica y otra normativa. Tal aserto conduce de la mano a la lógica formal y a la lógica deóntica instrumentos insuperables para descubrir algoritmos o formas mecánicas que aseguren la validez del razonamiento.

En lo que se refiere a las decisiones judiciales la lógica permite que su aplicación sea siempre condición necesaria de la validez deductiva de la sentencia y además en algunos casos se la podrá utilizar para aplicar informática de gestión mediante sistemas expertos que agilicen el servicio adecuado de justicia.

Esto ha de ocurrir primordialmente en los casos fáciles, donde la información acerca del contenido de las premisas normativa y fáctica es suficiente o se encuentra consensuada por las partes (en el caso del proceso penal son ejemplos el juicio abreviado y la denominada «probation»). Nos encontramos en ellos dentro del terreno de la racionalidad plena que adecuadamente aplicada permitirá resolver los conflictos con mayor rapidez y eficacia en lo que respecta a la adecuada fundamentación y justificación de las sentencias.

\section{Argumentos}

Son necesarios para lograr una fundamentación racional de las sentencias y especialmente para referimos a las que deben resolver casos difíciles. Los argumentos son secuencias de proposiciones que se derivan unas de otras por aplicación de reglas de inferencia (deducción) o por otras reglas (inducción, analogía). Hoy en día se considera que la argumentación puede encontrar apoyos no lógicos suficientes como para que no pierda racionalidad.

De cualquier modo las técnicas argumentativas (tan viejas como los sofistas expertos en modus tollens) no pueden descuidar la educación de las personas y en consecuencia de los procesos que forman o deforman su atención ya que siempre que se argumenta, lo hace alguien desde un punto de vista. No debe olvidarse que el de los operadores siempre es el punto de vista interno, lo que implica cierta aceptación del sistema normativo.

\section{Racionalidad práctica}

Hay razonamientos teóricos que son los estrictamente proposicionales y que funcionan con ciertos valores de verdad (descripciones acerca del esta- 
do del mundo), y otros prácticos que forman parte de deberes o de acciones donde los valores de verdad son más que dudosos ya que no existe en ellos descripción alguna que merituar confrontándola con una realidad. La racionalidad práctica se orienta sobre la base de fines que expresan deseos y preferencias de suerte tal que:

$\mathrm{X}$ quiere el estado de cosas $\mathrm{p}$ (premisa 1 ),

$X$ sabe que para llegar a $\mathrm{p}$ tiene que hacer $q$ (premisa 2);

$\mathrm{X}$ hace $\mathrm{q}$ (conclusión).

El razonamiento no es lógico (no hay valores de verdad en la premisa 1) pero es válido. Todos diríamos que si $\mathrm{X}$ es una persona normal, ha tenido «buenas razones» para hacer q. En nuestra vida cotidiana argumentamos de esta manera en forma constante.

El razonamiento argumental de los juristas es un razonamiento práctico. Se basa en argumentos que se justifican por «buenas razones». Allí encontramos una primer racionalidad instrumental que deberá ser acompañada por una segunda consistente en la razonabilidad en la elección de los fines (premisa 1)

\section{Contexto de descubrimiento y de justificación}

Los científicos sostienen que en la investigación hay dos fases diversas. La del descubrimiento y creación de una teoría que se puede explicar con base en motivos, circunstancias, prejuicios, trabajo, etc., pero que carece de toda posibilidad de ser formalizada de manera lógica. En cambio cuando el descubrimiento se integra en una teoría se lo debe justificar y ésta sí es una tarea lógica que implica corrección en los razonamientos $\mathrm{y}$ argumentos encadenados en forma deductiva.

En sentido similar los juristas dicen que la justificación interna es siempre lógica porque se refiere al paso de las premisas a la conclusión (contexto de justificación), pero que además se requiere una justificación externa que consiste en mostrar el carácter más o menos fundado de las premisas que integran el silogismo que concluye en la sentencia. Hay quienes niegan de plano racionalidad a esta tarea p. ej. los realistas norteamericanos que en general creen que la decisión judicial se encuentra siempre originada en motivos irracionales, subjetivos o emocionales y que luego, una vez hallada la solución, el aplicador procede a encontrar los argumentos que permitan justificarla.

\section{Casos difíciles}

Siguiendo a Atienza, diremos que lo son por cuatro motivos:

a. Problemas de relevancia: se duda sobre qué norma aplicar al caso 
b. Problemas de interpretación: se duda acerca de cómo debe entenderse la norma

c. Problemas de prueba: se duda acerca de la existencia de un hecho

d. Problemas de calificación: Se duda acerca de si un hecho cae dentro del supuesto de hecho de una norma.

$\mathrm{Si}$ se pretende resolver con certeza y previsibilidad o con racionalidad y razonabilidad que es lo mismo que pasar el primer test de eficiencia que la sociedad requiere, el operador no puede apoyarse en su autoridad porque la comunidad le pide buenas razones como fuente de sus argumentos. Y ello, además por cuanto es necesario aumentar el control público sobre las decisiones, circunstancia que habrá de contribuir no sólo a facilitar las apelaciones de las partes involucradas en el conflicto, sino también para aumentar la credibilidad pública en el sistema jurisdiccional.

Hay diversos modelos de solución de estos casos, los primeros de los cuales son los de la tópica o retórica (Viehweg, Perelman, Toulmin) que se centran en la persuasión y en un estudio más particularizado del auditorio pero que reflejan una gran ambigüedad y equivocidad, si bien no dejan de tener interés para quienes abogan frente a los jueces. Las técnicas para tratar los casos difíciles según los modelos más recientes (Aarnio, MacCormick, Alexy, Atienza) pasan por un primer paso que consiste en la identificación del problema, un segundo que consiste en ver si el mismo acaece porque existe insuficiente información o un exceso de información, un tercer paso que trata de construir hipótesis de solución y un cuarto que implica justificarla mediante argumentos (que pueden ser inductivos, abductivos, analógicos -tanto «a pari» como «a contrario»- etc.). Con ello se busca racionalidad instrumental y razonabilidad en cuanto a los argumentos contenidos en las premisas, en definitiva las mismas buenas razones que se advierten el razonamiento de $\mathrm{X}$ tal cual fuera expuesto precedentemente a guisa de ejemplo.

\section{El modelo cognoscitivo}

Ferrajoli considera a la jurisdicción como una garantía básica y en un modelo de derecho penal mínimo cree que debe buscarse una verdad procesal empíricamente controlable y controlada. Las garantías procesales funcionan así no sólo como de libertad sino también como de verdad. Por lo mismo pide por un juez espectador, popular y sabio que desconfíe del poder como fuente de la verdad. Requiere una epistemología falsacionista e insiste con la necesidad de articular todas las posibilidades para las contrapruebas de la defensa. De allí la irracionalidad de las pruebas legales que aseguran verdades inductivas y el carácter siempre probabilístico de la sentencia y la justificación relativa de la misma. 


\section{El modelo que parte de la dogmática}

El falsacionismo, epistemología a la que adhiere el autor citado pero que no es la única que puede servir de sostén a un modelo garantista, no resistió ataques duros de sus propios discípulos (Lakatos) ni tampoco soportó el embate sociohistórico, a la manera de Khun. La ciencia, de acuerdo a este autor, es un juego entre paradigmas, matrices disciplinares que fijan los objetos, las semánticas y los métodos y que sirven en tanto y en cuanto permitan ofrecer mejores explicaciones o ampliar el marco de los interrogantes a responder.

Esto mismo pasa con las teorías jurídicas (muy especialmente con la dogmática penal que representa tal vez el modelo teórico de mayor desarrollo en el mundo del derecho). A través de los modelos teóricos se observa el mundo, tal como el físico mira a través de su microscopio las imágenes que la teoría que adopta le hace esperar que aparezcan. No hay percepciones puras de hechos sino que éstos se encuentran conceptualmente enmarcados.

La asunción de las teorías depende de circunstancias históricas y de convicciones íntimas personales si bien habitualmente se suele elegir con cierta racionalidad a la de mayor poder explicativo, a la que refleja con mayor amplitud el campo de soluciones posibles a problemas concretos. No se puede pretender adoptar un modelo garantista si no se aspira a una sociedad abierta, que respete por igual todos los planes de vida, que trate a los sujetos con la misma consideración y respeto y que promueva activamente ciertas directrices políticas que mejoren la igualdad y la redistribución evitando en lo posible toda forma de dominación. La razonabilidad de los fines en un modelo de estas características surge por un consenso que produce aceptación, lo que requiere participar de teorías procesales o comunicativas que enmarquen una determinada situación de diálogo.

\section{Los principios y las reglas}

Si el garantismo como modelo teórico puede introducir razonabilidad a los fines mediante un cierto consenso al que se llega en el límite de alguna de las tesis citadas, habría que admitir que el derecho no se compone únicamente de normas, sino que además está integrado por principios que son superiores a ellas y que parten no solo del propio derecho sino también de pautas de moral y de política. De la conjunción entre reglas y principios se elaboran las teorías que los operadores necesitan para cumplir su misión de solucionar conflictos que suelen ser de suma 0 y que una mayor creatividad judicial transformaría en una maximización de las utilidades de las partes y una disminución de los costos que las mismas deben pagar. 
Las teorías así escogidas proporcionan un marco de justificación interno y externo y a través de las mismas se puede lograr un mayor control de la jurisdicción, con lo que se racionaliza el proceso. La mejor teoría será la que ofrezca las mejores razones en el marco de una cosmovisión y frente a una audiencia que sea receptiva. No existen demasiados modelos y tal vez no pueda acordarse entre ellos en las razones últimas, pero operativamente parece más útil sustituir la búsqueda de la verdad por la de la justificación y el acuerdo de manera que nuestras descripciones nos permitan una mejor relación con los otros. (Habermas o Rorty). Esto implica privilegiar la acción comunicativa por sobre la estratégica.

\section{Los jueces}

Hay muchos modelos de jueces posibles. Algunos de ellos son: Salomón que cree en una verdad sustancial, es inquisidor, arbitrario y discrecional y para el cual la verdad depende de su autoridad. Hércules el Juez de Dworkin que es el que se encuentra capacitado para encontrar la respuesta correcta para resolver casos difíciles, que siempre existen en el sistema y lo hace a través de una adecuada e íntegra ponderación de principios y reglas, en suma la verdad depende de su integridad. Herbert el Juez de Hart que se piensa a sí mismo como constreñido por grandes sectores de racionalidad, pero considera que no hay una respuesta correcta a casos difíciles, donde en cambio si existe discrecionalidad e imposibilidad de control y donde la verdad es arbitraria y depende de sus principios o prejuicios.

El modelo de Juez que surge de lo expresado en este artículo es el que explícitamente asume la mejor teoría disponible, la que mejor explica fenómenos diversos ampliando el orbe de soluciones, la que concuerda con su cosmovisión y sus principios morales y políticos. Luego a través de la misma observa los hechos del proceso y las reglas y principios del derecho con el fin de lograr una sentencia justificada, aceptable y consensuada sin que necesite para ello mencionar la verdad. En los casos fáciles la lógica será suficiente garantía y en los difíciles será la teoría elegida la que le ofrecerá los argumentos necesarios para justificar con razonabilidad y lograr argumentos apoyados en buenas razones. Sólo así pueden conseguirse los jueces sabios, populares, humanos e independientes que permitan el renacimiento del ideal de la Ilustración y a la par fortalezcan la credibilidad en el sistema. 